\title{
STUDY OF VANET ROUTING PROTOCOLS FOR END TO END DELAY
}

\author{
Sunilkumar M. Bhagat* and Dr Vijay Wadhai \\ PhD Scholar(Amravati University) Dept. of Information Technology, \\ MIT Academy of Engineering, Pune \\ bhagatsunilmegmail.com
}

\begin{abstract}
Less than a century since the automobile was made affordable enough for the general public, hundreds of millions of vehicles now travel along highways and streets around the world. Innovations in safety, comfort, and convenience have made vast improvements in automobiles during that time, and now new technologies promise to change the face of vehicular travel once again. Vehicular ad hoc network (VANET) is network which provides the communication between vehicle to vehicle for providing information to travelers with new features and applications that have never previously been possible. This paper focuses on vehicle to vehicle $(V 2 \mathrm{~V})$ communications in VANET. Lot of research is going on for determining route between source and destination vehicles for routing the information with good packet delivery ratio. In this paper we provide a simulation and study of VANET Routing Protocols for end-to-end delay in V2V communication.
\end{abstract}

\section{KEYWORDS}

V2V communication, V2I communication, wireless networks, MANET, VANET.

\section{INTRODUCTION}

A Vehicular Ad hoc Network( VANET) is kind of wireless ad hoc network. It is formed between vehicles for exchanging the information directly if vehicles are within range else sending the message through multi hop fashion. In this network vehicles are network nodes and equipped with wireless transceivers and computerized control modules. There are two types of VANET. In first type no infrastructure is needed where nodes perform vehicle-to-vehicle communication with each other. In other type Road Side Unit (RSU) are installed in this Vehicle can take advantage of RSU for routing information to other vehicles or serving as a gateway to the Internet as shown in figure 1 . In VANET the major challenge is high velocity at which vehicle move will sometimes create problem for information exchange. Major constraints for implementing VANET routing protocol is geographical and Traffic density. In city environment high buildings between roads which cause obstacles for radio signal. Where in case of high way, traffic density plays important role. In low traffic densities, vehicles tend to move at faster rates, but as traffic density increases, vehicles slow down. Very high traffic density also causes both 
relative speed and distance between vehicles to become stable moving in the opposite direction.[1,2]

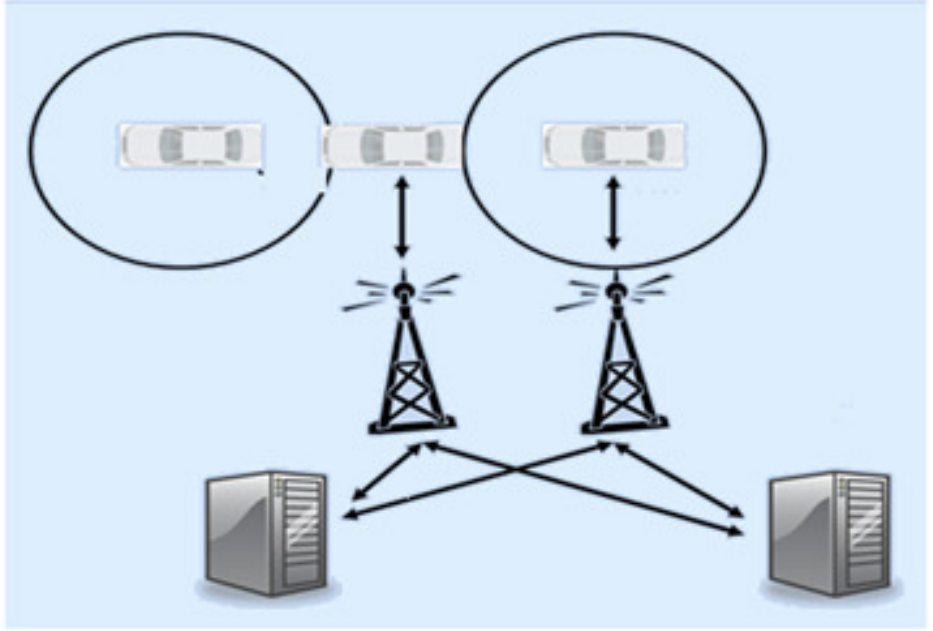

Figure 1. VANET Architecture

\section{RELATED WORK}

Because of the environmental constraints, high mobility of vehicles, traffic density driver behavior designing VANET routing protocol is a very challenging problem to search, maintain and update routing information, which is also one of the hottest topic among researchers . Many researchers have implemented VANET routing protocols and research results have been put forward which can be divided into following categories: Traditional ad hoc routing, Position Based Routing, Cluster based routing ,Broadcast base routing. Example of traditional routing are Dynamic Source Routing (DSR)and Ad-hoc On demand Distance Vector (AODV), but many researches show that most of them have poor performance when used in the vehicle network There are many researches in position based routing area such as Greedy Perimeter Stateless Routing (GPSR), Greedy Perimeter Coordinator Routing (GPCR) and so on. whereas. Clustering for Open IVC Networks and Location Routing Algorithm with Cluster-Based Flooding are belonging to these cluster based protocols and example of Broadcast based routing protocol are unicast routing protocols such as route discovery also use broadcast to find a valid path, Urban Multi-Hop Broadcast protocol (UMB) is one of the protocols that use broadcast to distribute packets. All broadcast based protocols need to consider the broadcast storm problem: Geocast routing such as Inter-Vehicles Geocast protocol (IVG) and Robust Vehicular Routing (ROVER), like position based multicast protocol, the basic idea of which are distributing message from the source node to some nodes in a special geographical region.[3]

\section{Simulation Platform}

QualNet is a network simulation tool that simulates wireless and wired packet mode communication networks. QualNet simulator used in the simulation of MANET, WiMax networks, satellite networks and sensor networks, among others. QualNet has models for common network protocols that are provided in source form and are organized around the OSI Stack. There are plenty of network simulators are available like NS2,OMNET++ etc. but we 
opted for QualNet because the user friendly support provided by QualNet with various protocols, environment factors, different terrains and analyzing capabilities are remarkable. A study done by Hsu et al compared performance results from a real world ad hoc wireless network deployment to the results obtained from a model of the network in QualNet and concluded that QualNet modeled the deployment scenario with remarkable accuracy, thus validating the ability of QualNet to model realistic wireless environmental effects as shown in figure 2.[4].

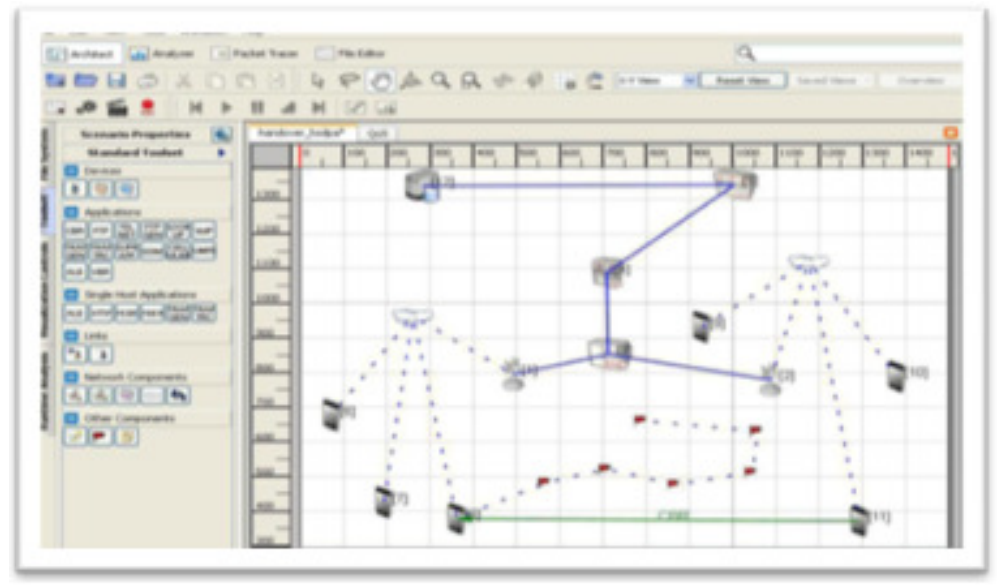

Figure 2. QualNet Design Mode

\section{ISSUES}

VANET has special characteristics and researchers have given more attention for implementing routing protocol but still many of the following issues need to be addressed for designing routing protocols [5]

- Frequent network disconnection

- Scalability

- Traffic density

- Obstacle

- Robust and reliable communication even at high vehicle speed

- Routing of Packets

- The hidden node problem

- End-to-End path between the source and the destination is not known in advance

\section{IMPLEMENTATION AND RESULT}

Here in our project implementation we have considered city environment scenario in QualNet as shown in Figure 3. 


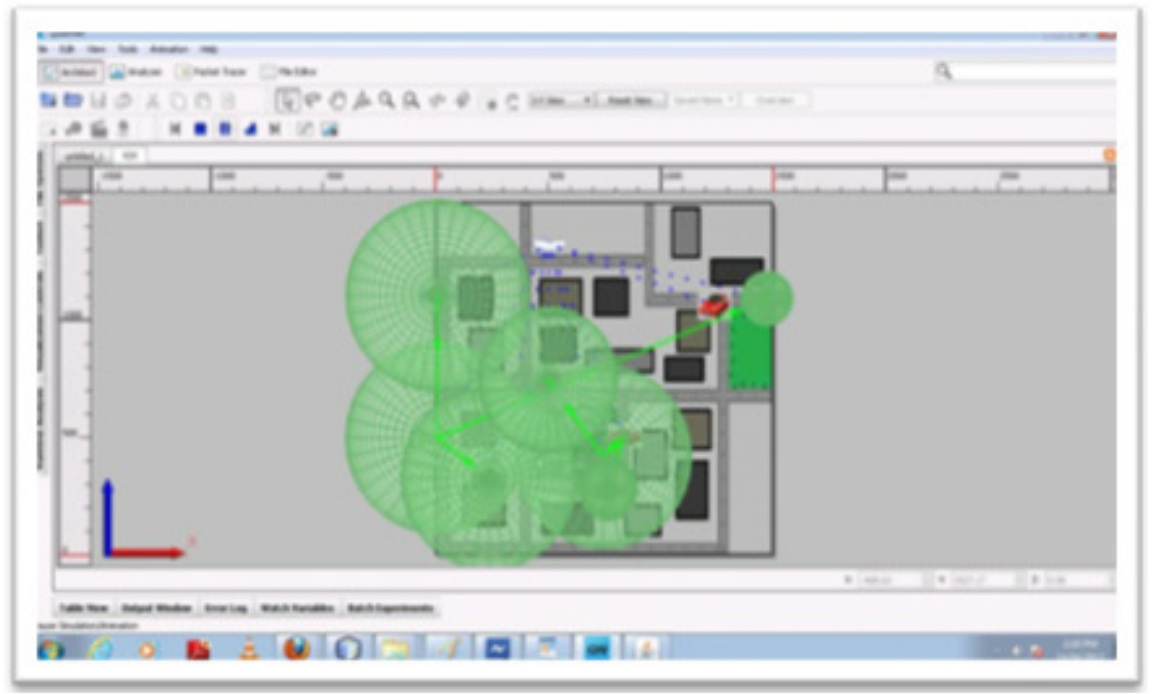

Figure 3. VANET Scenario using QualNet

In Our scenario we have studied and compared three different routing protocol AODV, Bellman Ford, DSR for different velocity and same number of packets to be sent between source node and destination node as shown in figure 4.

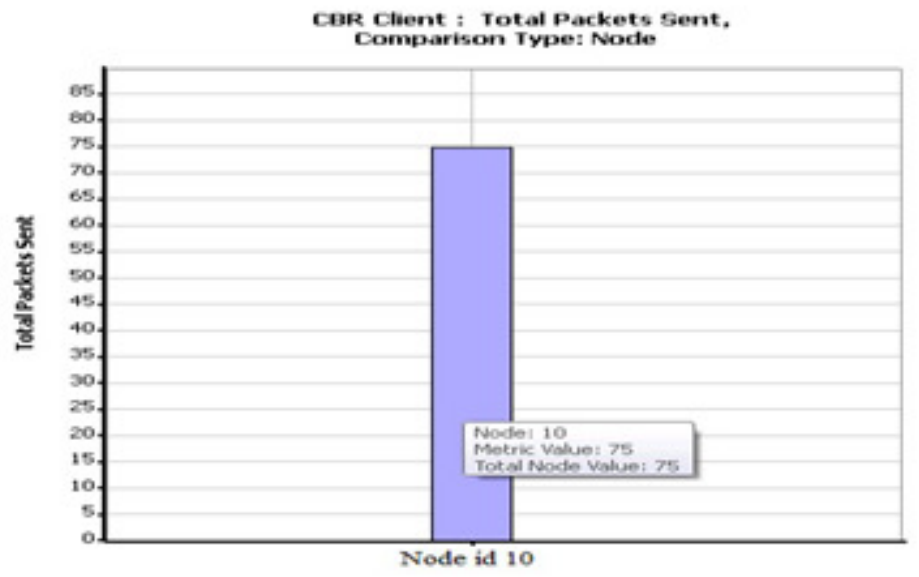

Figure 4 Packet sent by Source Node

Here is a comparison of total number of packets received for three routing protocols viz. AODV, Bellman Ford and DSR where the source and destination vehicles move with a speed of 6 meter $/ \mathrm{sec}$ and $10 \mathrm{~m} / \mathrm{sec}$ as shown in figure 5 . 


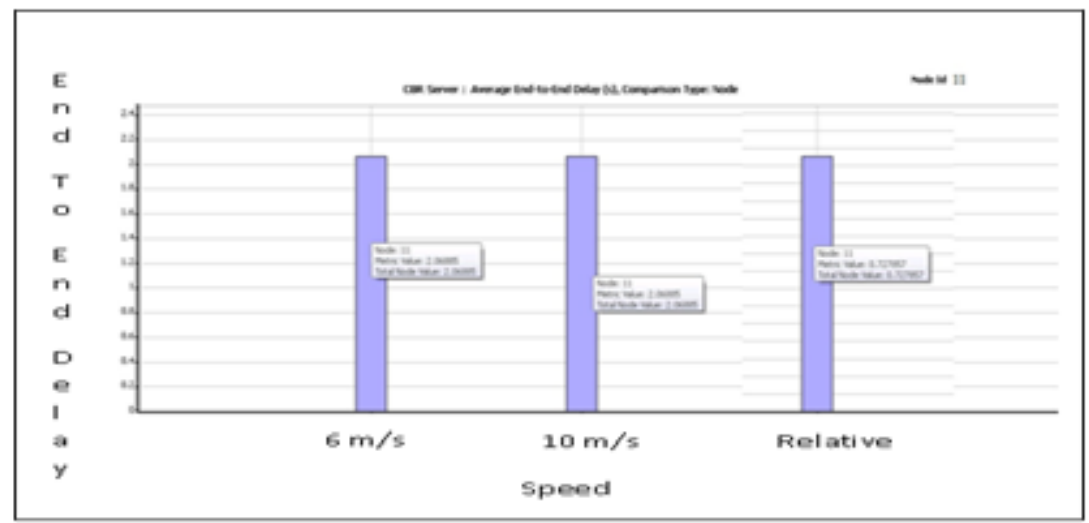

Figure 5. End to End delay for different velocity for DSR Protocol

Figure 5 shows the end to end delay using DSR Routing Protocol between source and destination node. Results are taken for 6 meter/second and other velocity for comparative study different routing protocol similarly figure 6 shows the end to end delay using Bellman ford Routing Protocol and Figure 7 shows the end to end delay using AODV routing Protocol

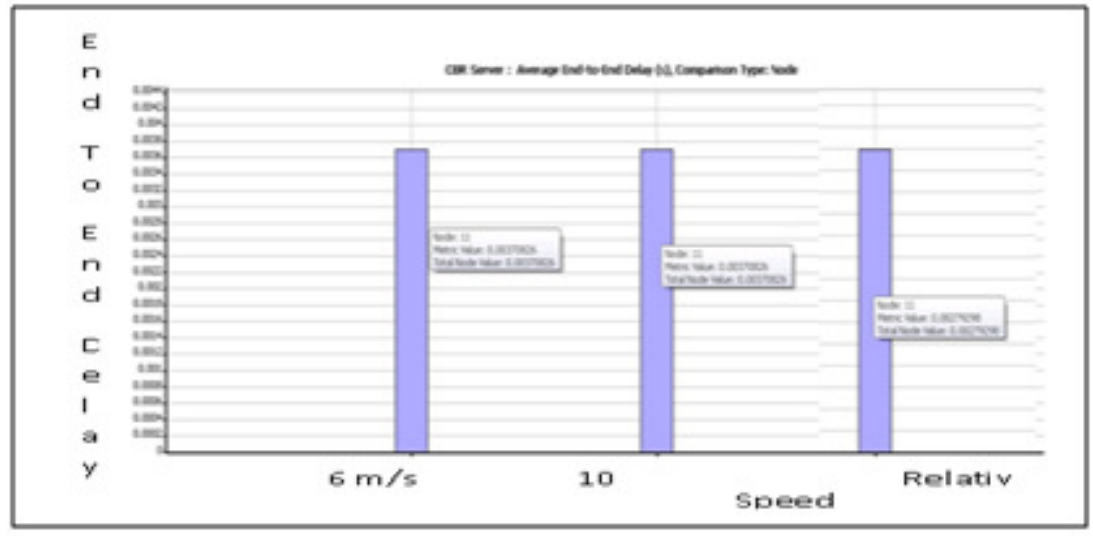

Figure 6. End to End delay for different velocity using Bellman Ford Protocol

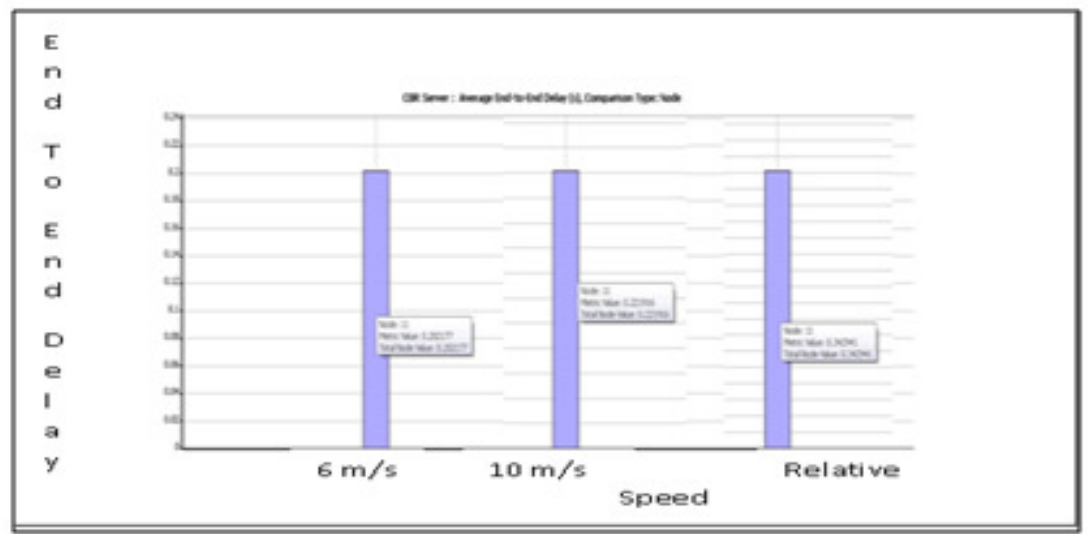

Figure 7. End to End delay for different velocity using DSR Protocol 
We compared these three protocol and found that Bellman ford routing protocol provides better performance in terms of end to end delay and packet lost.

\section{CONCLUSION}

Through our research work we can conclude that:

1. The Performance of Bellman ford routing protocol for $\mathrm{V} 2 \mathrm{~V}$ communication in urban scenario implemented using QualNet is better than other two protocols for end to end delay for all sets of velocity

2. Packet lost is also low at high velocity with very good throughput as compared to other two protocols.

3. Bellman ford is suitable for DSRC technology as compared to other two protocol

\section{ACKNOWLEDGEMENTS}

We take this opportunity to thank Dr. V. M. Thakare, Head Research Center, Amravati University for their valuable guidance and for providing all the necessary facilities. We would also like to thank institute( MIT Academy of Engineering ) for providing the required facilities, I

\section{REFERENCES}

[1] Kevin C. Lee, Uichin Lee, Mario Gerla"Survey of Routing Protocols in Vehicular Ad Hoc Networks", IEEE conference on VANET 2008

[2] Fan Li and Yu Wang, University of North Carolina at Charlotte "Routing in Vehicular Ad Hoc Networks: A Survey" IEEE Vehicular Technology Magazine, June 2007, pp 12-23

[3] Arzad Kherani and Ashwin Rao "Performance of Node-Eviction Schemes in Vehicular Networks" IEEE Transactions On Vehicular Technology, Vol. 59, No. 2, February 2010,pp 550-559

[4] R.S.Uppal, Shubhla Puri, Performance and Evaluation of IEEE 802.11e using QUALNET, (IJCSE, ISSN : 0975-3397 Vol. 3 No. 3 Mar 2011).

[5] Qing Yang • Alvin Lim • Shuang Li •Jian Fang • Prathima Agrawal "ACAR: Adaptive Connectivity Aware Routing for Vehicular Ad Hoc Networks in City Scenarios" Mobile Networks and Applications Volume 15 Issue 1, February 2010, pp 36-60

[6] James Bernsen, D. Manivannan "Unicast routing protocols for vehicular ad hoc networks: A critical comparison and classification" Journal on Pervasive and Mobile Computing in 2009 pp 1-18.

[7] Robert K. Schmidt and Tim Leinmüller,Elmar Schoch and Frank Kargl,Günter Schäfer, echnische "Exploration of Adaptive Beaconing for Efficient Inter vehicle Safety Communication" IEEE Network ,January/February 2010, pp14-20

[8] Parma Nand, Dr. S.C. Sharma, Performance study of Broadcast based Mobile Adhoc Routing Protocols AODV, DSR and DYMO, (Wireless Computing Research Lab, IIT Roorkee, INDIA, International Journal [9]Shahzad Ali, Sardar M Bilal, An Intelligent Routing Protocol for VANETs in City Environments, (COMSATS Institute of Information Technology Abbottabad, Pakistan) 